\title{
Differentiated Methodology of Training Long- Distance Swimmers for Competitions on Open Water Taking into Account Types of Energetic Metabolism
}

\author{
Ponimasov O.E. \\ Physical culture and sports training methodology \\ department \\ A.I. Gertsen Russian State Pedagogical University \\ St. Petersburg, Russia \\ o-pony@mail.ru
}

\author{
Bolotin A.E. \\ Physical culture theory and methodology department \\ Saint-Petersburg Polytechnic University of Peter The Great \\ St. Petersburg, Russia
}

\begin{abstract}
The article describes the questions of the training process quality improvement on the basis of training long-distance swimmers differentiated methodology taking into account types of athletes' energetic metabolism. As a result of the research work it was revealed that among the athletes, who have aerobic type of energetic metabolism, tempo endurance should be developed by means of standardcontinuous exercise method and their speed endurance should be developed by the repetitive method of training. Athletes, who have anaerobic type of energetic metabolism, can develop their tempo endurance by means of interval exercise method and their speed endurance by means of unlimited efforts method with normative quantity of distance parts repetitions. Among the athletes, who have mixed type of energetic metabolism tempo endurance should be developed by means of alternant method of training and speed endurance by means of combining repetitive method and unlimited efforts method with the fixed quantity of distance parts repetitions.
\end{abstract}

Keywords-swimming on open water; muscular activity energetic support; types of energetic metabolism; specialpreparatory stage of swimmer's training.

\section{INTRODUCTION}

Competitive activity of long-distance swimmers in open water places great demands on the level of their physical readiness [2]. The base of the specialized training for long distance swimming races forms special endurance development in overcoming the distance on water surface with high wave disturbance and not stable temperature regime [2]. The effectiveness of this physical quality development is determined by a purposeful influence on the athlete's organism by means on the basis of the energy production mechanisms type energetic metabolism [1, 3].

Sufficient amount of research works, concerning this problem, only indirectly discuss the questions of energy supply peculiarities in muscular activity of long-distance swimmers. This contradiction doesn't let us use special endurance development means and methods differentially in long-distance swimming [4]. The methods of special endurance development among swimmers in open water are not fully used. They are differentiated relative to typology of athletes' energetic metabolism.

The aim of the research is to reveal the effectiveness of athletes' specialized training methodologies in swimming on open water taking into account the types of energetic metabolism.

\section{RESEARCH METHODOLOGY}

18 athletes-masters of sport, who specialize in open water swimming at 5 and $25 \mathrm{~km}$ distance, took part in the research. The age range of the respondents was 17-20 years old. For the created variants of training testing 4 groups of athletes were formed depending on the type of energetic metabolism: aerobic type, anaerobic type, mixed type, not taking into consideration energy supply of the work. The duration of the experiment was 6 weeks of special-preparatory period of training. Means and methods of specialized training for each group of athletes were created taking into consideration the characteristics of muscular activity energy supply mechanism. In order to substantiate the model of training swimmers comparative analysis of athletes' functional abilities was held in different groups, differentiated according to the type of energetic metabolism.

For the research objectives realization the method of functional state and athletes' reserve capacities expressdiagnostics (S.A. Dushanin, 1998) D\&K-Test was used. As a result of the program algorithms functioning we defined the type of each athlete energetic metabolism on the basis of the character and height of electrocardiogram $\mathrm{R}$ - and $\mathrm{S}$-waves analysis. Electrocardiogram was made in 3 main, 3 increasing and 6 chest leads. The received results helped to calculate the following indices. 
program planning among swimmers taking into account heart rate and the tempo of energetic metabolism.

TABLE I. MAIN PARAMETERS OF LONG-DISTANCE SWIMMERS LOAD AT A SPECIAL-PREPARATORY STAGE OF TRAINING FOR COMPETITIONS (6 WEEKS) percentage)

Capacity of energy supply (CASE) aerobic source index characterizes the ability to fulfill the load in the $1^{\text {st }}$ and the $2^{\text {nd }}$ zones of intensity.

The index of aerobic recycling capacity (ADT) characterizes athletes' propensity for aerobic work (in percentage).

General metabolic capacity index (TMC) characterizes general working capacity of an organism.

The index of creatine phosphate energy supply power (PCPES) characterizes speed qualities of swimmers.

The index of glycolytic energy supply power (GPC) characterizes speed endurance of swimmers.

The index of aerobic energy supply power (PAE) characterizes the ability to demonstrate general endurance and also to rehabilitate oneself after anaerobic work.

The index of anaerobic metabolism threshold (AMT) characterizes the effectiveness of aerobic energy supply mechanisms use.

The effectiveness of the training process control was achieved owing to special training methodologies differentiation among long-distance swimmers depending on the characteristics of energy supply of their muscular activity.

Tempo endurance of aerobic type swimmers developed by means of continuous long-term exercise method, speed endurance by means of repetitive method of training.

Among athletes with anaerobic type of energy metabolism tempo endurance developed by means of interval exercise method, speed endurance by means of submaximal loads with the fixed amount of the swum parts repetitions.

Swimmers with the mixed type of energetic metabolism developed their tempo endurance by means of alternating method of training and speed endurance by means of repetitive method and unlimited efforts method combination with the fixed amount of distance parts repetitions.

For the control group of long-distance swimmers standard means and methods of tempo and speed endurance development were used.

The load for long-distance swimmers was chosen taking into account current result in 400 meters swimming (table I) and 1500 meters swimming (table II). The number of repetitions of the parts that an athlete swims and weekly volume of the training load were selected taking into account the level of athletes' functional state. For special training control the system of training process control created by G.G. Turetskiy (2000) was used. It included power testing at a special bench, lactate profile determination, Skin fold test and blood profile analysis. The system was used for training

\begin{tabular}{|c|c|c|c|c|}
\hline \multirow{2}{*}{$\begin{array}{c}\text { Parameters } \\
\text { of the load }\end{array}$} & The groups of respondents according to the type of energetic \\
metabolism
\end{tabular}

\section{III.RESULTS}

As a result of the research works there were revealed differences in the dynamics of specialized tests indices depending on the types of long-distance swimmers energetic metabolism (table II, III).

TABLE II. DYNAMICS OF RESULTS IN 400 METERS SWIMMING AMONG LONG-DISTANCE SWIMMERS OF DIFFERENT ENERGETIC METABOLISM TYPES (C)

\begin{tabular}{|c|c|c|c|c|}
\hline $\begin{array}{c}\text { Period of } \\
\text { testing } \\
\text { at a special- } \\
\text { preparatory } \\
\text { stage of } \\
\text { training }\end{array}$ & \multicolumn{4}{|c|}{ The groups of respondents according to the type of } \\
\cline { 2 - 5 } & $\begin{array}{c}\text { energetic metabolism } \\
\text { type }\end{array}$ & $\begin{array}{c}\text { Anaerobic } \\
\text { type }\end{array}$ & Mixed type & $\begin{array}{c}\text { Without } \\
\text { taking into } \\
\text { account } \\
\text { types of } \\
\text { metabolism }\end{array}$ \\
\hline $\begin{array}{c}\text { The } \\
\text { beginning of } \\
\text { the stage }\end{array}$ & $309,8 \pm 5,4$ & $319,4 \pm 4,8$ & $315,0 \pm 10,7$ & $310,8 \pm 8,6$ \\
\hline $\begin{array}{c}\text { The end of } \\
\text { the stage }\end{array}$ & $291,8 \pm 3,5$ & $302,8 \pm 6,3$ & $302,4 \pm 12,3$ & $296,1 \pm 5,8$ \\
\hline
\end{tabular}

In 400 meters swimming athletes of aerobic type energetic metabolism showed time results improvement for 17,9 seconds, the results increase was 5,8 \% $(\mathrm{P}<0,05)$. Longdistance swimmers with the mixed type of energetic metabolism improved their result for 12,6 seconds, the increase was 4,0\% $(\mathrm{P}<0,05)$. The groups of anaerobic energetic metabolism type showed time index improvement for 16,6 seconds, the increase was $5,2 \%(\mathrm{P}<0,05)$. The average time improvement in this test among the group of swimmers without taking into account type of energetic 
metabolism was 10,8 seconds. It corresponds with the increase for $3,5 \%(\mathrm{P}<0,01)$.

TABLE III. THE RESULTS DYNAMICS IN 1500 METERS SWIMMING AMONG LONG-DISTANCE SWIMMERS OF DIFFERENT ENERGETIC METABOLISM TYPES (SECONDS)

\begin{tabular}{|c|c|c|c|c|}
\hline $\begin{array}{c}\text { Period of } \\
\text { testing } \\
\text { at a } \\
\text { special- } \\
\text { preparatory } \\
\text { stage of } \\
\text { training }\end{array}$ & $\begin{array}{c}\text { The groups of respondents according to the type of energetic } \\
\text { metabolism }\end{array}$ & \multicolumn{4}{|c|}{$\begin{array}{c}\text { Without } \\
\text { type }\end{array}$} & $\begin{array}{c}\text { Anaerobic } \\
\text { type }\end{array}$ & Mixed type & $\begin{array}{c}\text { taking into } \\
\text { account type } \\
\text { of } \\
\text { metabolism }\end{array}$ \\
\cline { 2 - 5 } $\begin{array}{c}\text { The } \\
\text { beginning } \\
\text { of the stage }\end{array}$ & $1155,4 \pm 18,4$ & $1214,6 \pm 11,8$ & $1203,3 \pm 16,8$ & $1157,7 \pm 20,2$ \\
\hline $\begin{array}{c}\text { The end of } \\
\text { the stage }\end{array}$ & $1098,4 \pm 11,6$ & $1156,9 \pm 22,2$ & $1148,8 \pm 14,5$ & $1118,8 \pm 21,4$ \\
\hline
\end{tabular}

In 1500 meters swimming the athletes with aerobic type of energetic metabolism improved the average time of distance overcoming for 56,6 seconds, the increase was $4,9 \%$ $(\mathrm{P}<0,05)$. The swimmers with the mixed type of energetic metabolism showed time indices decrease for 54,1 seconds, the increase was 4,5\% $(\mathrm{P}<0,05)$. The respondents with anaerobic type of energetic metabolism improved the average result for 58,6 seconds, the increase was 4,7\%. The average time decrease in this test among the athletes from the group without taking into account the type of energetic metabolism was 38,5 seconds, which corresponds with $3,3 \%(\mathrm{P}<0,01)$ increase.

Table 4 presents the results of estimating functional and reserve capacities of athletes' organism before and after special-preparatory stage of training long-distance swimmers.

\section{TABLE IV. FUNCTIONAL AND RESERVE CAPACITIES DYNAMICS OF LONG-DISTANCE SWIMMERS AS A RESULT OF SPECIAL-} PREPARATORY STAGE OF TRAINING

\begin{tabular}{|c|c|c|c|c|}
\hline \multirow[b]{2}{*}{$\begin{array}{l}\text { Period } \\
\text { of } \\
\text { testing }\end{array}$} & \multicolumn{4}{|c|}{$\begin{array}{l}\text { The groups of respondents according to the type of energetic } \\
\text { metabolism }\end{array}$} \\
\hline & Aerobic type & Mixed type & $\begin{array}{c}\text { Anaerobic } \\
\text { type }\end{array}$ & $\begin{array}{c}\text { Without taking } \\
\text { into account } \\
\text { type of } \\
\text { metabolism } \\
\end{array}$ \\
\hline \multicolumn{5}{|c|}{ Anaerobic metabolic capacity (CANSE), c.u. } \\
\hline before & $45,42 \pm 13,68$ & $71,07 \pm 6,9$ & $124,65 \pm 8,96$ & $76,12 \pm 34,63$ \\
\hline after & $48,96 \pm 11,23$ & $76,9 \pm 4,89$ & $136,1 \pm 11,32$ & $82,52 \pm 9,15$ \\
\hline $\mathrm{t}$ & 0,62 & $2,19 *$ & $2,44^{*}$ & 0,84 \\
\hline \multicolumn{5}{|c|}{ Aerobic metabolic capacity (CASE), c.u. } \\
\hline before & $240,1 \pm 21,36$ & $229,5 \pm 17,63$ & $204,41 \pm 21,69$ & $226,65 \pm 29,49$ \\
\hline after & $260 \pm 18,13$ & $249,5 \pm 13,68$ & $218,92 \pm 18,67$ & $244,85 \pm 16,83$ \\
\hline $\mathrm{t}$ & $2,22 *$ & $2,89 *$ & 1,38 & $2,50 *$ \\
\hline \multicolumn{5}{|c|}{ General metabolic capacity (TMC), c.u. } \\
\hline before & $285,5 \pm 12,3$ & $300,6 \pm 21,42$ & $329,06 \pm 22,18$ & $302,78 \pm 34,07$ \\
\hline after & $308,52 \pm 14,38$ & $326,4 \pm 19,22$ & $355 \pm 23,01$ & $327,65 \pm 18,87$ \\
\hline $\mathrm{t}$ & $4,10 * *$ & $2,98 * *$ & $2,34 *$ & $2,98 * *$ \\
\hline \multicolumn{5}{|c|}{ Power of creatine phosphate energy supply (PCPES), c.u. } \\
\hline before & $31,54 \pm 2,35$ & $29,55 \pm 1,95$ & $38,75 \pm 2,26$ & $32,64 \pm 5,93$ \\
\hline after & $34,79 \pm 2,167$ & $32,03 \pm 2,19$ & $41,93 \pm 2,12$ & $35,57 \pm 2,16$ \\
\hline $\mathrm{t}$ & $3,23 * *$ & $2,96 * *$ & $2,86^{*}$ & $2,17 *$ \\
\hline \multicolumn{5}{|c|}{ Power of glycolytic source of energy supply (GPS), c.u. } \\
\hline
\end{tabular}

\begin{tabular}{|c|c|c|c|c|}
\hline before & $31,60 \pm 2,65$ & $29,52 \pm 2,47$ & $33,5 \pm 2,03$ & $31,28 \pm 3,19$ \\
\hline after & $34,35 \pm 2,76$ & $31,94 \pm 2,03$ & $35,77 \pm 1,58$ & $33,75 \pm 2,12$ \\
\hline $\mathrm{t}$ & $2,35^{*}$ & $2,47^{*}$ & $2,35^{*}$ & $3,00^{* *}$ \\
\hline \multicolumn{5}{|c|}{ Power of aerobic source of energy supply (PAE), c.u. } \\
\hline before & $57,48 \pm 4,43$ & $52,12 \pm 5,80$ & $46,39 \pm 4,03$ & $51,62 \pm 10,60$ \\
\hline after & $62,25 \pm 3,22$ & $56,03 \pm 6,13$ & $51,63 \pm 4,34$ & $56,28 \pm 8,96$ \\
\hline $\mathrm{t}$ & $2,63^{*}$ & 1,60 & $2,57^{*}$ & 1,56 \\
\hline \multicolumn{2}{|c|}{ Notes: **-P $<0,01 ; *-\mathrm{P}<0,05$} \\
\hline
\end{tabular}

Thus, as a result of the differentiated methodology of training use among long-distance swimmers we revealed valid increase of the organism functional and reserve capacities. It also should be noted that in terms of no valid CANSE and PAE indices increase in the group of athletes without taking into account type of energetic metabolism, there was valid increase of these indices in the groups of the mixed and anaerobic types of energetic metabolism. The received results help to come to understand the effectiveness of the differentiated methodology of training long-distance swimmers for swimming on open water taking into account the types of energetic metabolism.

\section{IV.CONCLUSION}

As a result of special-preparatory stage of training realization for the competitions among long-distance swimmers with different types of energetic metabolism different reaction of an organism to the training load was stated. The athletes with anaerobic and mixed type of energetic metabolism quicker adapt to speed-power work and swimmers with aerobic type of energetic metabolism - to a long-term work for endurance. It proves that taking into account the typology of long-distance swimmers energetic metabolism can be the base for means and methods of training determination among athletes in swimming on open water.

\section{References}

[1] Bakayev V.V., Bolotin A.E. and Chunguang You. Reaction of vegetative nervous system to loads among female long - distance runners with different fitness level. Journal of Human Sport and Exercise. 2018, vol. 13(2), pp. 245-252.

[2] Bakayev V.V., Bolotin A.E. and Aganov S.S. Comparative analysis of the changes in blood chemistry among long-distance swimmers during workouts at middle and low altitudes. World congress of performance analysis of sport XII (September, 19-23, 2018, Opatija, Croatia. 2018, pp. 39-42.

[3] Bolotin A.E. and Bakayev V.V. Method for training long distance runners taking into account bioenergetic types of energy supply for muscular activity., the 5-th International Congress on sport sciences research and technology support (icSPORTS 2017) (30-31 October, 2017, Funchal, Madeira, Portugal). 2017, pp. 126-131.

[4] Bolotin A.E. and Bakayev V.V. Scientific and theoretical prerequisites for improvement of modern pedagogical technologies, In book: Advanced Learning and Teaching Environments - Innovation, Contents and Methods - Publisher: IntechOpen. 2018, pp. 195-221.

[5] Aleksandr S. Kuznetsov. Russian Professor's meeting. Russian Journal of Physical Education and Sport. 2019, vol. 14(1), pp. 17-22. DOI: 10.14526/2070-4798-2019-14-1-18-24.

[6] Aleksandr S. Kuznetsov, Evgeniya N. Usmanova, Oksana V. Kolomytseva. Athletes' psychological-physiological indices study in different specializations at the stages of sports career crises overcoming. Russian Journal of Physical Education and Sport. 2019, vol. 14(2), pp. 81-87. DOI: 10.14526/2070-4798-2019-14-2-89-96. 